\title{
Angiohistiocitoma de Células Multinucleadas
}

\author{
André Melícia', Sara Lestre Sara Lestre², Elvira Bártolo 3 \\ 'Médico Interno de MGF, USF Alcais, Cascais, Portugal \\ ${ }^{2}$ Assistente Hospitalar. Unidade Funcional de Dermatologia, Hospital de Cascais, Cascais, Portugal \\ ${ }^{3}$ Assistente Graduada Sénior e Dermatopatologista. Serviço de Anatomia Patológica, Hospital de Cascais, Cascais, Portugal
}

RESUMO - O angiohistiocitoma de células multinucleadas ( $A C M$ ) é uma entidade rara, cuja patogenia não está completamente compreendida. É mais comum em mulheres de meia-idade e caracteriza-se por pápulas ou nódulos eritematovioláceos, habitualmente assintomáticos e localizados predominantemente nas extremidades. O diagnóstico é fundamentalmente histopatológico, consistindo em alterações típicas na derme, nomeadamente na proliferação de pequenos vasos e na presença de células gigantes multinucleadas. A sua evolução é benigna, embora persistente, havendo poucos casos relatados de remissão espontânea.

Apresenta-se o caso de um homem de 48 anos com diagnóstico de ACM, manifestando-se por pápulas e nódulos assintomáticos, agrupados no dorso de ambas as mãos, com um ano de evolução. O diagnóstico foi determinado pelo exame histopatológico, excluindo-se outros diagnósticos diferenciais. Com este relato de caso pretende-se contribuir para o conhecimento sobre esta patologia e destacar a complementaridade entre a observação clínica e a análise histopatológica.

PALAVRAS-CHAVE - Histiocitoma Fibroso Benigno; Neoplasias da Pele.

\section{Multinucleate Cell Angiohistiocytoma}

ABSTRACT - Multinucleated cell angiohistiocytoma (MCAH) is a rare clinical entity whose pathogenesis is not fully understood. It is more common in middle-aged women and is characterized by erythematoviolaceous papules or nodules, usually asymptomatic and predominantly located in the extremities. Histopathology is essential for making the diagnosis, consisting of typical alterations in the dermis, namely the proliferation of small vessels and the presence of multinucleated giant cells. Evolution is benign, although persistent, with few reported cases of spontaneous remission.

We present the case of a 48-year-old man with MCAH, who exhibited asymptomatic papules and nodules grouped on the back of both hands, with a year of evolution. The diagnosis was made after histopathology, which excluded other differential diagnoses. With this case report, we intend to contribute to the knowledge about this entity and highlight the interconnection of clinical observation and histopathologic analysis.

KEYWORDS - Histiocytoma, Benign Fibrous; Skin Neoplasms.

\section{INTRODUÇÃO}

O angiohistiocitoma de células multinucleadas (ACM), descrito pela primeira vez por Smith e Wilson Jones, ' é uma doença rara e benigna, que ocorre principalmente em mulheres de meia-idade. ${ }^{2}$ Clinicamente caracteriza-se por pápulas ou nódulos, geralmente assintomáticos, de cor que pode variar entre o vermelho e o castanho. As lesões podem surgir agrupadas ou isoladas, mais frequentemente localizadas nas extremidades, existindo poucos casos de ACM generalizado. . $^{3,4}$

A sua patogenia não é completamente compreendida, sendo a hipótese predominante a de se tratar de um processo reativo. ${ }^{2}$ Histopatologicamente observa-se, na derme superior, a proliferação de pequenos vasos no seio de um estroma denso de colagénio, composto por células fibrohistiocíticas intersticiais e células gigantes multinucleadas de contornos espiculados, que, apesar de ser um achado típico, não é patognomónico. ${ }^{2,4} \mathrm{O}$ estudo imunohistoquímico, não sendo fundamental, pode ajudar no diagnóstico. Com alguma variabilidade, as células gigantes multinucleadas apresentam positividade para a vimentina, fator XIIla e para - CD68 e são negativas para o fator VIII, CD34 e S100. As células endoteliais, além de marcarem positivo para o
Correspondência: André Melícia

Rua Rio das Grades

2645-559 Alcabideche, Portugal

E-mail:andremelicia1@gmail.com

DOI: https://dx.doi.org/10.29021/spdv.78.4.1247
Recebido/Received 2020/07/03

(c) Autor (es) (ou seu (s) empregador (es)) 2020 Revista SPDV. Reutilização permitida de acordo com CC BY-NC. Nenhuma reutilização comercial.

(C) Author(s) (or their employer(s)) 2020 SPDV Journal. Re-use permitted under CC BY-NC. No commercial re-use. 


\section{Caso Clínico}

fator VIII, CD31 e CD34, podem revelar positividade para - CD68. Por sua vez, as células mononucleares intersticiais marcam positivo para vimentina, fator XIIla, MAC387 e lisozima. ${ }^{2,4,5}$

A evolução das lesões é lenta e progressiva, havendo relatos de casos em que se verificou remissão espontânea. ${ }^{6} \mathrm{O}$ impacto para o doente é fundamentalmente estético. ${ }^{5}$

A maior revisão da literatura sobre a apresentação clínica e histopatológica do $\mathrm{ACM}$ realizada até à data reportou um total de 142 casos, em 2015. ${ }^{2}$ Em Portugal, existem apenas dois artigos publicados na literatura. ${ }^{7,8}$

\section{CASO CLÍNICO}

Doente de 48 anos, do sexo masculino, observado por três lesões nodulares, assintomáticas, com um ano de evolução, localizadas inicialmente na mão esquerda, com extensão à mão direita.

Apresentava história pessoal de hipertensão arterial, gota, trombocitopenia familiar e hipertrigliceridémia. Mantinha como medicação habitual perindopril, alopurinol e sinvastatina. Negava história de traumatismo. Sem alergias alimentares ou medicamentosas conhecidas.

No exame objetivo observavam-se nódulos e pápulas, no dorso de ambas as mãos, assintomáticos, de cor eritematoviolácea, de consistência dura e sem aumento da temperatura à palpação, alguns esboçando bordo elevado e regular, com depressão central (Fig.s 1 e 2). Não existiam outras alterações de relevo no restante tegumento.

Perante as hipóteses de diagnóstico de eritema elevatum diutinum, de granuloma anular e de ACM, foi realizada biópsia cutânea que mostrou, na derme superficial e média, proliferação de pequenos vasos, de parede fina, rodeados por uma camada de pericitos. Na derme circundante, observam-se células multinucleadas e angulosas, em estroma de colagénio espessado (Fig. 3), características típicas de ACM, diagnóstico que foi assumido.

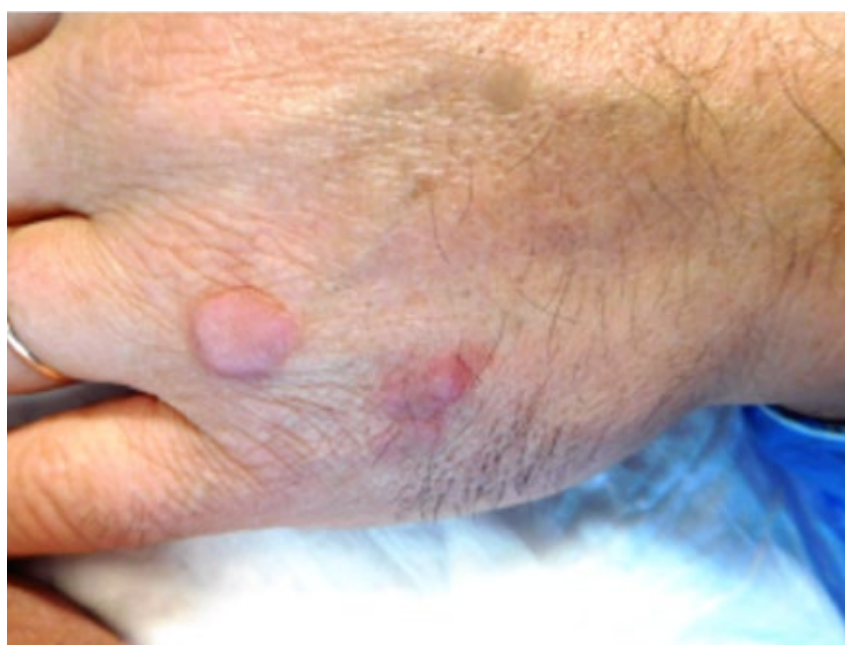

Figura 1 - Nodulos eritematovioláceos, de consistência dura à palpação, esboçando bordos elevados na mão direita.

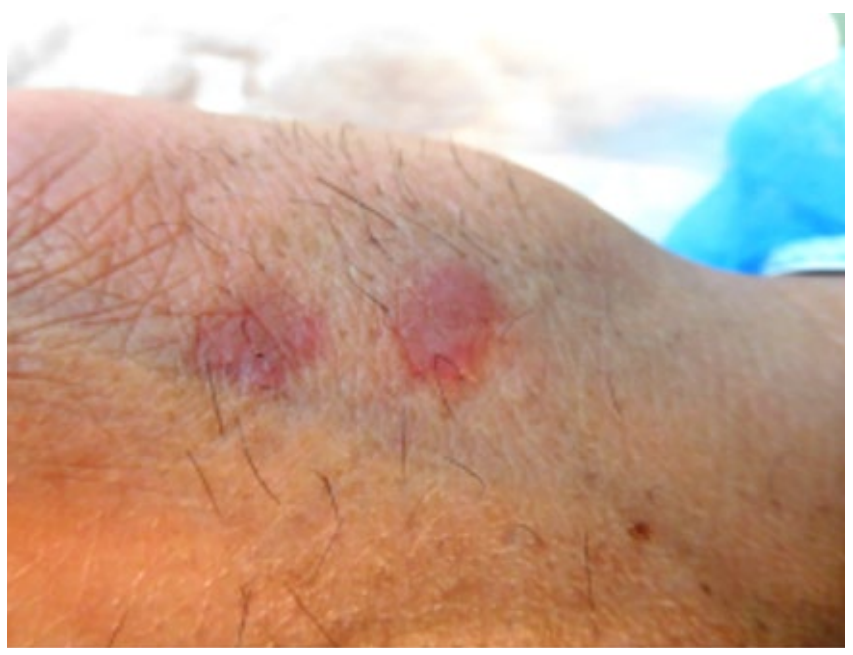

Figura 2 - Um nódulo e várias pápulas confluentes, eritematosas, no dorso da mão esquerda.

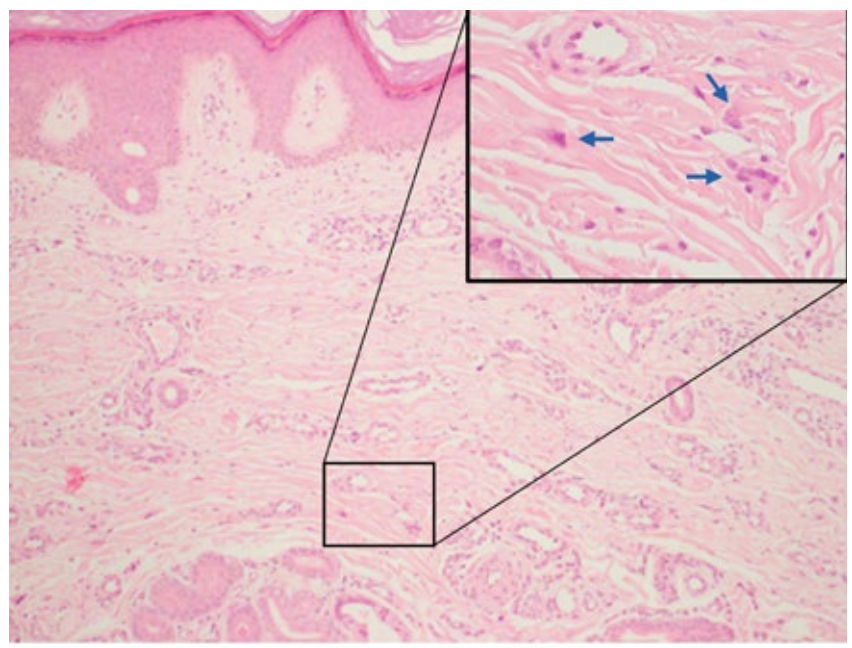

Figura 3 - Imagem histopatológica mostrando proliferação de vasos pequenos, de parede fina, rodeados por uma camada de pericitos na derme superficial e média (H\&Ex100). Em detalhe evidência de células multinucleadas e angulosas em estroma de colagénio espessado $(\mathrm{H} \& \mathrm{Ex} 400)$

doente foi reobservado após um mês, mantendo as lesões no dorso das mãos. Após explicação sobre a benignidade e evolução indolente das lesões o doente mostrou-se tranquilizado, optando-se por não realizar tratamento.

\section{DISCUSSÃO}

O angiohistiocitoma de células multinucleadas é uma dermatose rara, cujo diagnóstico parte da suspeição clínica e é confirmado pela presença de características histopatológicas distintas. Pensa-se que resulte inicialmente de um estímulo inflamatório e subsequente proliferação vascular, surgindo mais tardiamente um processo de fibrose e atrofia. $^{2}$ Cesinaro et al ${ }^{9}$ propuseram ainda que os estrogénios desempenham um fator determinante no desenvolvimento 
das lesões, o que justificaria a predominância desta doença no sexo feminino. De facto, numa revisão sistemática de 142 casos, Frew ${ }^{2}$ relatou que $79 \%$ dos doentes eram do sexo feminino. Contudo, nem todos os casos reportados demonstraram sobrexpressão dos recetores de estrogénio. ${ }^{3,5}$ Além disso, Roy et al, ${ }^{10}$ numa série de casos recente, não encontraram uma diferença significativa entre géneros, com $51,6 \%$ dos indivíduos do sexo feminino. De maneira semeIhante, também o presente caso, referente a um indivíduo do sexo masculino, coloca em causa a influência da hormona feminina na patogenia do ACM.

A apresentação clínica do ACM caracteriza-se por lesões rosadas, violáceas ou acastanhadas, tumefactas, múltiplas e de tamanho variável (2-15 mm), geralmente unilaterais, em forma de cúpula ou com superfície achatada, podendo coalescer e formar uma estrutura em anel. ${ }^{4}$ Apesar de a dermatoscopia não ter sido documentada neste caso, nas lesões de ACM podem observar-se áreas de cor avermelhada intercaladas com áreas esbranquiçadas e zonas mais periféricas com um padrão reticulado fino. ${ }^{11}$ Embora estas características sejam pouco específicas, a dermatoscopia pode ser útil na exclusão de outros diagnósticos. ${ }^{7}$ No presente caso, as lesões tinham bordos bem definidos e elevados, algumas esboçando uma depressão central, iniciando-se no dorso da mão esquerda e surgindo posteriormente no dorso da mão direita. Pela sua semelhança clínica com o ACM, foram colocados diagnósticos diferenciais de eritema elevatum diutinum e granuloma anular clássico. Estas entidades afetam frequentemente as extremidades, nomeadamente a face dorsal das mãos, formando lesões assintomáticas, isoladas ou múltiplas, geralmente bilaterais. ${ }^{12,13} \bigcirc$ granuloma anular clássico faz parte das doenças granulomatosas cutâneas. Já o eritema elevatum diutinum é uma vasculite de pequenos vasos. Estes diagnósticos são, assim, facilmente distinguidos através da análise histopatológica. Histopatologicamente, o ACM faz ainda diagnóstico diferencial com dermatofibroma atrófico, que clinicamente se manifesta por lesão única, o que permitiu excluir de imediato este diagnóstico, e com sarcoma de Kaposi, que se caracteriza pela presença de fendas vasculares irregulares, presença de plasmócitos e ausência de células gigantes multinucleadas. ${ }^{14}$

O ACM é uma doença tendencialmente crónica, de evolução lenta e de carácter benigno. ${ }^{3,5} \mathrm{O}$ seu diagnóstico assenta na importância da correlação clínica e histopatológica. Não foram identificadas características histológicas de malignidade. ${ }^{3}$ Existem casos raros de envolvimento generalizado do tegumento ${ }^{3}$ e ainda alguns casos de envolvimento extracutâneo, nomeadamente envolvimento da órbita ${ }^{15} \mathrm{e}$ da mucosa oral. ${ }^{16}$ Não é necessário qualquer tratamento e não existem terapêuticas formalmente definidas, havendo alguns relatos de remissão espontânea. ${ }^{6}$ Contudo, o doente pode procurar tratamento por razões estéticas, existindo casos descritos de sucesso terapêutico com a remoção cirúrgica, crioterapia, laser pulsado de contraste, laser Argon, luz intensa pulsada e laser $\mathrm{CO} 2$, sendo a evidência científica limitada. ${ }^{5}$
Deste relato de caso destaca-se o facto de se tratar de um indivíduo do sexo masculino, o que questiona a etiopatogenia do ACM no que respeita ao papel dos estrogénios. Pretende-se também contribuir para a divulgação dos aspetos do diagnóstico e prognóstico desta entidade clínica rara, que é exemplificativa da importância da correlação clinicopatológica em Dermatologia.

Conflitos de interesse: Os autores declaram a inexistência de conflitos de interesse na realização do presente trabalho.

Fontes de financiamento: Não existiram fontes externas de financiamento para a realização deste artigo.

Confidencialidade dos dados: Os autores declaram ter seguido os protocolos da sua instituição acerca da publicação dos dados de doentes.

Consentimento: Consentimento do doente para publicação obtido.

Proveniência e revisão por pares: Não comissionado; revisão externa por pares.

Conflicts of interest: The authors have no conflicts of interest to declare.

Financing support: This work has not received any contribution, grant or scholarship.

Confidentiality of data: The authors declare that they have followed the protocols of their work center on the publication of data from patients.

Patient Consent: Consent for publication was obtained.

Provenance and peer review: Not commissioned; externally peer reviewed

ORCID

André Melícia

https://orcid.org/0000-0003-2056-0008

Sara Lestre

https://orcid.org/0000-0002-3913-0422

Elvira Bártolo

https://orcid.org/0000-0002-8342-2836

\section{REFERÊNCIAS}

1. Smith NP, Jones EW. Multinucleate cell angiohistiocytoma - a new entity. Br J Dermatol. 1985; 113:15-15. doi:10.1111/j.1365-2133.1985.tb12966.x

2. Frew JW. Multinucleate cell angiohistiocytoma: clinicopathological correlation of 142 cases with insights into etiology and pathogenesis. Am J Dermatopathol. 2015; 37:222-8. doi:10.1097/DAD.0000000000000075

3. Wang $M$, Abdul-Fattah B, Wang C, Zhao Y, Qu X, Al-Muriesh $M$, et al. Generalized multinucleate cell angiohistiocytoma: case report and literature review. J Cutan Pathol. 2017; 44:125-34. doi:10.1111/cup.12853

4. Pérez LP, Zulaica $A$, Rodríguez L, Campo MC, Peñaranda JM, Fernández-Redondo V, et al. Multinucleate cell angiohistiocytoma. Report of five cases. J Cutan Pathol. 2006; 33:349-52. doi:10.1111/i.0303-6987.2006.00428.x

5. Grgurich E, Quinn K, Oram C, McClain R, Lountzis 


\section{Caso Clínico}

N. Multinucleate cell angiohistiocytoma: Case report and literature review. J Cutan Pathol. 2019; 46:59-61. doi:10.1111/cup. 13361

6. Cribier B, Gambini C, Rainero M, Grosshans E. Multinucleate cell angiohistiocytoma. A review and report of four cases. Acta Derm Venereol. 1995; 75:337-9. doi:10.2340/0001555575337339

7. Teixeira V, Serra D, Pereira N, Tellechea O. Multinucleate cell angiohistiocytoma: a new case report with dermoscopy. Dermatol Online J. 2014; 20:3.

8. Rato M, Monteiro AF, Parente J, Aranha J. Case for diagnosis. Multinucleated cell angiohistiocytoma. An Bras Dermatol. 2018; 93:291-3. doi:10.1590/abd18064841.20186821

9. Cesinaro AM, Roncati L, Maiorana A. Estrogen receptor alpha overexpression in multinucleate cell angiohistiocytoma: new insights into the pathogenesis of a reactive process. Am J Dermatopathol. 2010; 32:655-9. doi: 10.1097/DAD.0b013e3181d3ca49

10. Roy SF, Dong D, Myung P, McNiff JM. Multinucleate cell angiohistiocytoma: A clinicopathologic study of 62 cases and proposed diagnostic criteria. J Cutan Pathol. 2019; 46:563-9. doi: 10.1111/cup. 13463

11. Valerón-Almazán P, Dehesa L, Santana N, Vilar J,
Carretero G. Hallazgos dermatoscópicos del angiohistiocitoma de células multinucleadas: ¿una variante de dermatofibroma? Actas Dermo-Sifiliográficas. 2011; 102:69-71. doi:10.1016/i.ad.2010.04.013

12. Thornsberry LA, English JC. Etiology, Diagnosis, and Therapeutic Management of Granuloma Annulare: An Update. Am J Clin Dermatol. 2013; 14:279-90. doi:10.1007/ s40257-013-0029-5

13. Gibson LE, el-Azhary RA. Erythema elevatum diutinum. Clin Dermatol. 2000; 18:295-9.doi: 10.1016/S0738-081X(99)00120-0

14. Sass U, Noel JC, André J, Simonart T. Multinucleate cell angiohistiocytoma: report of two cases with no evidence of human herpesvirus- 8 infection. J Cutan Pathol. 2000; 27:258-61. doi:10.1034/i.1600-0560.2000.027 005258.x

15. Shields JA, Eagle RC, Shields CL, Sohmer KK. Multinucleate Cell Angiohistiocytoma of the Orbit. Am J Ophthalmol. 1995; 120: 402-3. doi:10.1016/S00029394(14)72178-6

16. Rawal YB, Anderson KM, Rawal SY. Multinucleate cell angiohistiocytoma: an uncommon mucosal tumour. Clin Exp Dermatol. 2009; 34:333-6. doi:10.1111/i.13652230.2008.02939.x 